\title{
SABERES DOCENTES E COMPLEXIDADE: EM BUSCA DE UMA NATUREZA COMUM
}

\author{
Maria José de Pinho \\ Bruno Leite da Silva \\ Universidade Federal de Tocantins (Brasil)
}

\begin{abstract}
Resumo. O presente artigo tem o objetivo de apresentar os conceitos de saberes docentes trabalhados por Maurice Tardif e indagá-los acerca de sua natureza para que se possa compreender seu sentido nuclear e, assim, buscar sua ampliação a partir do pensamento complexo de Edgar Morin. Dessa forma, constrói-se um debate sobre o contexto social em que tais saberes são formados, o papel do próprio sujeito na construção desses saberes e, posteriormente, uma aproximação entre o pensamento de Tardif e Morin. Para tanto, realizou-se uma pesquisa bibliográfica com abordagem qualitativa, viabilizando o confronto das perspectivas dos dois autores. Como resultado, propõe-se uma perspectiva conceitual complementar, mediante a qual se reconheça a complexidade dentro da formação dos saberes docentes, considerando os operadores cognitivos da mesma.
\end{abstract}

Palavras-chave: Saberes docentes, formação docente, complexidade.

\section{TEACHER KNOWLEDGES AND COMPLEXITY: IN SEARCH FOR A COMMON NATURE}

\begin{abstract}
This article presents the concepts of teacher knowledges included in the works of Maurice Tardif, and to inquire about its nature so that its nuclear meaning can be comprehended, and thus seek its magnification from the complex thinking of Edgar Morin. In this way, we promote a debate about the social context in which such knowledges are formed, the role of the subject in the construction of these knowledges and, subsequently, an approximation between the thought of Tardif and Morin. To that end, a bibliographical research with a qualitative approach was carried out, making possible the confrontation of the two authors' perspectives. As a result, we propose a new perspective which recognizes the complexity within the teacher knowledge formation, taking into account its cognitive operators.
\end{abstract}

Keywords: Teacher Knowledges, Teacher Formation, Complexity.

\section{SABERES DOCENTES Y COMPLEJIDAD: EN BÚSQUEDA DE UNA NATURALEZA COMÚN}

Resumen: Este artículo tiene como objetivo presentar los conceptos de saberes docentes trabajados por Maurice Tardif, e indagar acerca de su naturaleza para que se pueda comprender su sentido nuclear y, así, buscar su ampliación a partir del pensamiento complejo de Edgar Morin. De ese modo, se construye un debate sobre el contexto social en el que se forman tales saberes, el papel del propio sujeto en la construcción de esos saberes y, posteriormente, una aproximación entre el pensamiento de Tardif e Morin. Para tal efecto, se realizó una investigación bibliográfica con un enfoque cualitativo, viabilizando la confrontación de las perspectivas de los dos autores. Como resultado, se propone una nueva perspectiva 
mediante la cual se pueda reconocer la complejidad dentro de la formación de los saberes docentes, considerando también los operadores cognitivos que en ella intervienen.

Palabras clave: Saberes docentes, Formación Docente, Complejidad.

\section{Introdução}

Este artigo discute os conceitos e a natureza ${ }^{\mathrm{i}}$ dos saberes docentes na perspectiva de Maurice Tardif, para demonstrar que a perspectiva do pensamento complexo de Edgar Morin proporcionaria um maior aprofundamento desses conceitos, pois, além de ser saberes provenientes da formação profissional, saberes disciplinares, curriculares e experienciais, é necessário considerar que eles surgem de um sistema complexo. Realizar-se-á, portanto, uma aproximação entre as teorias dos dois pensadores, a fim de aprofundar a compreensão sobre a natureza dos saberes docentes, fomentando um novo diálogo.

Procura-se, também, analisar a noção do professor como sujeito, bem como o macro sistema social contemporâneo que envolve sua prática, no sentido de compreender como os docentes mobilizam os saberes inerentes à sua profissão. Esse propósito complementar desta pesquisa é justificado em função da complexidade que permeia a referida mobilização, já que cada docente detém diferentes saberes advindos de diversos âmbitos, diferenciando a sua constituição como sujeito.

Nessa perspectiva, o professor, como sujeito, só faz sentido se for incluso em um ecossistema. Deve-se, portanto, compreender a pluralidade do sujeito a partir de sua inserção em um ambiente, sendo que seu processo histórico e de experiência comportam uma de suas diversas facetas, o que evita simplificar sua constituição como resultado exclusivo de um processo de formação ou julgar seu sucesso ou fracasso dependente unicamente dele mesmo. Dessa forma, a pergunta que norteia este artigo é: qual a natureza dos saberes que são mobilizados pelos professores em suas práticas?

Maurice Tardif, pesquisador canadense, desenvolve uma linha de pensamento que nos proporciona uma caracterização e algumas possibilidades de compreender os saberes docentes, fugindo dos enfoques puramente psicológicos, bem como dos pautados pelas tendências tecnicistas ou de concepções sociológicas tradicionais para repensar os fundamentos sociocognitivos do ensino e, assim, trazer uma nova concepção para os saberes docentes.

De acordo com Tardif (2012), os saberes docentes não podem ser confundidos com uma mera atuação de transmissão de conhecimentos previamente estabelecidos. A prática dos docentes, por sua vez, integra um grande número de saberes que irão se relacionar das mais variadas formas. Tardif (2012, p. 36) afirma a possibilidade de

“... definir o saber docente como um saber plural, formado pelo amálgama, mais ou menos coerente, de saberes oriundos da formação profissional e de saberes disciplinares, curriculares e experienciais."

O pensamento complexo, por sua vez, é considerado uma referência para a superação da cegueira do conhecimento, anunciada por Morin (2007) e que se perpetua 
na educação durante séculos, centrando-se muito mais na reprodução de conteúdos que no bem-estar das pessoas, da sociedade e da natureza (Zwierewicz e Torre, 2009).

Os conceitos que se vinculam ao pensamento complexo contrapõem-se aos princípios cartesianos de fragmentação do conhecimento, propondo, em seu lugar, outra forma de pensar os problemas contemporâneos (Santos, 2009), o que colabora para a superação do pensamento reducionista, que, para Morin (2004), não apreende a multidimensionalidade das realidades.

Ao aproximar o pensamento complexo da constituição do professor como um sujeito, a autonomia delimita-se como um tema central para reconhecê-lo como um sujeito complexo que está inserido num ecossistema, dada sua dependência das condições sociais, biológicas e culturais. Nesse sentido, Morin (2005) reforça que um sujeito se constitui ao aprender uma linguagem, uma cultura, além de destacar a relevância da complexidade desses elementos para que se possa fazer escolhas entre o arcabouço das ideias existentes e refletir de maneira autônoma.

Para a análise das perspectivas de Tardif sobre os saberes docentes e a reinterpretação pelo viés do pensamento complexo de Morin, prioriza-se a pesquisa bibliográfica, apoiada pela abordagem qualitativa. Espera-se que os resultados colaborem para compreender a complexidade implicada na constituição e na atuação dos docentes e sirvam para elucidar reflexões sobre sua formação.

\section{Metodologia da pesquisa}

Tendo como objetivos debater a construção dos saberes docentes propostos por Tardif, a noção do professor como sujeito e o macro sistema social contemporâneo, observando a sua constituição como sujeito à luz do pensamento complexo, este estudo constitui-se em uma pesquisa bibliográfica de abordagem qualitativa. Justifica-se essa ênfase pelo caráter subjetivo do objeto estudado, buscando, a partir dele, interpretar as raízes do processo de formação docente e os saberes mobilizados por esses sujeitos em sua prática.

Minayo (1994, p. 21) lembra que a abordagem qualitativa

“... trabalha com o universo de significados, motivos, aspirações, crenças, valores e atitudes o que corresponde a um espaço mais profundo das relações, dos processos e dos fenômenos que não podem ser reduzidos à operacionalização de variáveis."

A ideia de realizar este estudo se deu após uma aproximação do conceito de saberes docentes de Maurice Tardif e do pensamento complexo de Edgar Morin, em relação ao tratamento de uma natureza da formação do sujeito e de uma percepção das interações que implicam nesse processo, o que, no pensamento complexo, compreende a ligação entre o todo e suas partes, e, no pensamento de Maurice Tardif, na reflexão sobre a formação dos saberes docentes e suas diversas origens - técnicas, sociais, pessoais, didáticas, entre outras. 
A pesquisa bibliográfica foi determinante nesse processo, reafirmando a importante função que Gil (2008) lhe atribui, sendo desenvolvida a partir de material previamente elaborado sobre o objeto em questão. $\mathrm{O}$ autor lembra que

"Embora em quase todos os estudos seja exigido algum tipo de trabalho desta natureza, há pesquisas desenvolvidas exclusivamente a partir de fontes bibliográficas." (Gil, 2008, p. 65).

Assim, a pesquisa bibliográfica foi empregada como tipo de pesquisa deste artigo, sendo que a apreensão do referencial teórico explorado teve como marco inicial a obra de Tardif 'Saberes docentes e formação profissional' (Tardif, 2012), que possibilitou um aprofundamento sobre os saberes docentes e sua origem. Nessa incursão, foi possível notar que esse pensador se orientou pela pluralidade de saberes e, a partir desse caminho teórico, levou-nos ao pensamento complexo moriniano e a sua obra 'A religação dos saberes: o desafio do século XXI', para poder estabelecer um princípio de um diálogo fecundo.

A leitura de outras obras de Morin que explicitam o pensamento complexo complementaram o estudo, entre elas, 'Educação e complexidade, os sete saberes e outros ensaios' e 'O método 3: o conhecimento do conhecimento' (Morin, 2005a, Morin, 2015b). Elas proporcionaram o encontro de alguns de seus pilares - os operadores cognitivos -, transparecendo uma possível ligação entre esses operadores e a formação dos saberes docentes proposta por Tardif.

A pesquisa bibliográfica realizada neste artigo contou, principalmente, com as obras citadas e suas respectivas análises e interpretações. A reunião das reflexões e todo o processo teórico serviram de base para esta busca de uma melhor interpretação da origem dos saberes docentes e sua compreensão em um mundo complexo e interligado, levantando a importância da multiplicidade de condições que constituem os docentes, sua relevância social e autonomia.

\section{Resultados e discussão}

Considerando os objetivos desta pesquisa, destacam-se, inicialmente, os saberes docentes na perspectiva de Tardif. A partir de então, prioriza-se a constituição do professor e sua autonomia, destacando a complexidade dos saberes docentes.

\section{Sobre os saberes docentes}

Ao abordar a atuação profissional dos docentes, Tardif (2012) classifica os saberes que permeiam esse processo em quatro grupos. São eles:

- $\quad$ Saberes da formação profissional: compreendem um conjunto de saberes que são transmitidos pelas próprias instituições que formam os professores;

- $\quad$ Saberes disciplinares: relacionam-se com os diversos campos do conhecimento na perspectiva da disciplina e, por sua vez, são determinados e escolhidos pela universidade, acabando por incorporar-se à própria prática docente; 
- Saberes curriculares: correspondem aos objetivos, discursos, métodos e conteúdos por meio dos quais a instituição escolar forma categorias e proporciona os saberes sociais determinados como modelos da cultura erudita e de sua formação;

- Saberes experienciais: determinam-se a partir da experiência vivida pelo professor e são validados nesse mesmo âmbito, acoplando a vivência individual e social sob a forma de habitus e de habilidades, do saber-fazer e do saber ser. É através de tais saberes, relacionados com as práticas docentes, que os professores se tornam um grupo social e profissional.

A partir de suas pesquisas, Tardif (2012) buscou compreender as impressões que os professores têm sobre os seus próprios saberes, partindo do pressuposto de que o saber é plural e advém de diversas fontes, como citado acima. Tendo a pluralidade dos saberes como ponto de partida, ele discorre que só haverá coerência nessa classificação se ela se referir à natureza diversa de suas origens, com as diferentes formas de aquisição e relações que ocorrem entre professores e seus saberes. Na Tabela 1, sistematizam-se as fontes de aquisição dos saberes docentes e modos de integração no trabalho.

Tabela 1

Fontes de aquisição dos saberes docentes e modos de integração no trabalho

$\begin{array}{ccc}\text { Saberes dos professores } & \text { Fontes sociais de aquisição } & \begin{array}{c}\text { Modos de integração no } \\ \text { trabalho docente }\end{array}\end{array}$

\begin{tabular}{|c|c|c|}
\hline nesconic & $\begin{array}{l}\text { A família, o ambiente de vida, a } \\
\text { educação no sentido lato etc. }\end{array}$ & \\
\hline professores. & A escola primária e secundária, & $\begin{array}{l}\text { Pela história de vida e pela } \\
\text { socialização primária. }\end{array}$ \\
\hline $\begin{array}{l}\text { Saberes provenientes } \\
\text { formação escolar anterior. }\end{array}$ & $\begin{array}{l}\text { os estudos pós-secundários não } \\
\text { especializados etc. }\end{array}$ & $\begin{array}{l}\text { Pela formação e pela } \\
\text { socialização pré-profissionais. }\end{array}$ \\
\hline $\begin{array}{l}\text { Saberes provenientes da } \\
\text { formação profissional para } \mathrm{o} \\
\text { magistério. }\end{array}$ & $\begin{array}{l}\text { Os estabelecimentos de } \\
\text { formação de professores, os } \\
\text { estágios, os cursos de reciclagem } \\
\text { etc. }\end{array}$ & $\begin{array}{llr}\text { Pela formação e } & \text { pela } \\
\text { socialização profissional } & \text { nas } \\
\text { instituições de formação } & \text { de } \\
\text { professores. } & & \end{array}$ \\
\hline $\begin{array}{l}\text { Saberes provenientes dos } \\
\text { programas e livros didáticos } \\
\text { usados no trabalho. }\end{array}$ & $\begin{array}{l}\text { A utilização das 'ferramentas' } \\
\text { dos professores: programas, } \\
\text { livros didáticos, cadernos de }\end{array}$ & $\begin{array}{l}\text { Pela utilização das 'ferramentas' } \\
\text { de trabalho, sua adaptação às } \\
\text { tarefas. }\end{array}$ \\
\hline $\begin{array}{l}\text { Saberes provenientes de sua } \\
\text { própria experiência na profissão, } \\
\text { na sala de aula e na escola. }\end{array}$ & $\begin{array}{l}\text { A prática do ofício na escola e } \\
\text { na sala de aula, a experiência dos } \\
\text { pares etc. }\end{array}$ & $\begin{array}{l}\text { Pela prática do trabalho e pela } \\
\text { socialização profissional. }\end{array}$ \\
\hline
\end{tabular}

Nota: Fonte: Tardif (2012, p. 63)

As informações registradas na Tabela 1 demonstram a preocupação do autor em correlacionar os saberes docentes, utilizados pelos professores na sua atividade profissional, com suas naturezas, demonstrando que o resultado de sua 'forma de atuação' é fruto de uma vasta interação que reúne diversos fatores. Nota-se a existência de relações com naturezas distintas sendo trabalhadas em um único fenômeno, às vezes 
oriundas de uma formação profissional, às vezes de experiências práticas com seus saberes individuais e percebe-se, ainda, a referência a saberes instrumentais.

Todos esses saberes, de certa forma, interagem por meio de uma gama de relações, o que reforça a ideia do autor de que os saberes docentes são sociais e não se enquadram em uma simples construção que pode ser criada e repassada dentro de uma formação simplista e redutora, recusando um discurso distante da realidade em que tais condutas seriam apreendidas e trariam o 'sucesso' para sua prática e para sua função.

Mesmo que, na maioria das vezes, a atuação em sala de aula seja protagonizada por um único professor, todo o seu histórico de relações constituídas em sua experiência social, familiar, cultural, histórica e a sua relação com os alunos, outros professores e, até mesmo, com a instituição escolar e de formação vão influir em suas ações.

Para Tardif (2012), os saberes docentes têm origens diversas. Por isso, o autor critica algumas posturas que apresentam os saberes docentes como um conjunto de disposições que, de certa forma, permitiria que o professor as escolhesse nos momentos em que julgasse ideal. Mesmo considerando sua contribuição para uma caracterização dos saberes dos professores, o autor acredita que essa é uma análise simplificadora e que desconsidera a relação entre o tempo e a constituição dos saberes, questão fundamental para compreender a genealogia dos saberes docentes dado que,

“... além de marcadores afetivos globais conservados sob a forma de preferências ou de repulsões, os indivíduos dispõem, antes de mais nada, de referenciais de tempo e de lugares para indexar e fixar essas experiências na memória." (Tardif, 2012, p. 67).

Assim, as experiências vividas durante a escolarização ou socialização se tornam marcas que podem se transformar em orientações positivas ou negativas de conduta na prática profissional, convertendo a temporalidade em constituição da própria consciência e composição de uma parte da origem dos saberes docentes.

$\mathrm{O}$ autor enfatiza o tempo na construção dos saberes devido à relevância encontrada na pré-formação do profissional no período de socialização escolar, dado que é a partir da formação de seus valores e suas crenças que o sujeito constitui e orienta seus hábitos. Essa construção não acontece de forma linear, uma vez que não existe uma simples sobreposição de experiências, mas tal efeito se constrói de forma seletiva pelos sujeitos.

\section{Professor: sujeito e autonomia}

Compreende-se que os professores, como sujeitos, estão inseridos em um sistema complexo, o que faz surgir a necessidade de se refletir sobre a profissão para que se possa ampliar a compreensão da prática docente. Deve-se ter em mente que o professor é um ser múltiplo, de várias identidades e personalidades, que contém um todo social e é, também, parte de uma sociedade.

Determinar um sujeito pode ser uma tarefa muito árdua na concepção tradicional da ciência - ou seja, no paradigma da simplificação, porque em tudo o que haja determinismos, não haverá sujeito, consciência ou autonomia. Conceber a ideia de sujeito, assim, é, de acordo com Morin (2005), uma questão de se colocar em seu próprio mundo, de encontrar o 'eu' e se determinar, diferentemente de determinar o 'eu' 
do outro. É necessário ocupar o seu lugar e ser, ao mesmo tempo, autônomo e dependente, ser concebido de forma 'aberta' e compreendido de maneira 'complexa'.

Assim, a autonomia é um tema central para reconhecer o professor como um sujeito complexo que está inserido em um ecossistema, dado que ela depende de condições que são sociais, biológicas e culturais, pois

“... para sermos nós mesmos precisamos aprender uma linguagem, uma cultura, um saber, e é preciso que essa própria cultura seja bastante variada para que possamos escolher no arcabouço das ideias existentes e refletir de maneira autônoma." (Morin, 2005, p. 66).

Destarte, o professor é um sujeito não só formado por essa malha complexa, mas também um ator fundamental na construção de um sistema que proporcione a autonomia dos outros sujeitos que estão nas salas de aula. Destaca-se, portanto, a identidade profissional como um fragmento contido no desenvolvimento do professor como um sujeito, com diversos aspectos que vão influenciar diretamente na construção dessa identidade e, consequentemente, em suas implicações. Dentre tais aspectos, destacam-se compromisso, abertura para aprender e ensinar, credos, valores, conhecimentos teóricos, didática, experiências de vida e profissionais. Outrossim,

“... a formação docente tem que ser pensada como um aprendizado profissional ao longo da vida, o que implica envolvimento dos professores em processos intencionais e planejados, que possibilitem mudanças em direção a uma prática efetiva em sala de aula.” (André, 2010, p. 176).

De certo, não seria possível identificar tais atores sem ao menos compreender que sua constituição é complexa e múltipla. A identidade surge, dessa forma, nos entraves das relações sociais. Cada sujeito constrói sua identidade no reconhecimento e na experiência.

Para compreender melhor os saberes mobilizados pelos professores, deve-se ter noção de que sua identidade é formada nos traços complexos do tecido que os circunda e que, assim, constituem-se como sujeitos do conhecimento. Essa compreensão já leva à quebra da visão tradicional de que tais sujeitos têm sua atividade diretamente ligada à de um técnico que simplesmente repassa os conhecimentos produzidos por outras pessoas.

Tardif (2012) afirma que, em contrapartida, os professores não podem ser vistos apenas como meros atores sociais que teriam uma única função na sociedade e cuja atividade é determinada, exclusivamente, por mecanismos sociológicos. Isto é, os professores não podem ser reconhecidos como fantoches, como instrumento para atender a uma classe dominante e reproduzir sistemas sociais ou influenciar diretamente uma luta de classes. Para o autor, essas visões são redutoras, ao passo que

... para compreender a natureza do ensino, é absolutamente necessário levar em conta a subjetividade dos atores em atividade, isto é, a subjetividade dos 
próprios professores. Ora, um professor de profissão não é somente alguém que aplica conhecimentos produzidos por outros, não é somente um agente determinado por mecanismos sociais. (Tardif, 2012 p. 230).

Em outras palavras, uma visão redutora do mundo inibe a visão dos sujeitos. Como também já questionado por Morin, ao criticar a exclusão do sujeito das análises realizadas através da lente do paradigma simplificador, criar-se-ia uma visão turva do professor e da educação pela sociedade, a saber, do professor como mero reprodutor do conhecimento.

Em virtude de tais levantamentos, é possível afirmar que a autonomia e a identidade do professor devem ser levadas em conta quando se pondera sobre os saberes docentes e que, para além disso, faz-se necessário evitar o pensamento reducionista como princípio determinante das relações entre tais saberes.

Segundo Morin (2015), os seres vivos, o homem e a sociedade são sistemas auto-organizadores que se autoproduzem initerruptamente, de forma autônoma, mas alicerçando-se na sujeição do meio ambiente. Reconhecendo os sistemas - vivos, sociais ou humanos - como autoeco-organizadores, surge o princípio da autonomia/dependência ${ }^{i i}$ ou, como o autor denomina, da auto-organização, configurando-se como uma das bases do próprio pensamento complexo.

A autonomia, portanto, vai se constituir de forma relativa, considerando que uma liberdade absoluta e livre de qualquer dependência seria impossível, face à necessidade de interação com o ambiente para que a própria autonomia seja constituída. Como resultado, a autonomia do sujeito é dependente do ambiente em que vive não só em aspectos sociais, mas históricos e biológicos.

A ideia de sujeito, para Morin (2015), leva em conta um pressuposto biológico por estar ligada a um ser vivo, devendo, portanto, considerar seus princípios. Dessa forma, a constituição do sujeito autônomo - no caso deste estudo, o sujeito professor refere-se à visão de uma dependência biológica entre ele e o ambiente em que se encontra no meio social e cultural. A perspectiva de sujeito se apresenta cada vez mais complexa à medida que ele interatua ${ }^{\text {iii }}$ no mundo, necessitando de uma contraposição de si no ambiente para afirmar-se. Em outras palavras, o sujeito depende do externo para retornar a 'si'. Ademais, o sujeito tem uma vasta composição em seu caráter existencial, uma pluralidade de personalidades e potencialidades diversas.

A partir daí, a autopoiese ${ }^{\text {iv }}$ se apresenta como um conceito de suma importância para compreender a subjetividade da formação dos professores, pois leva a uma reflexão sobre o ensino como um todo (Santos, 2008), dado que todo ser vivo é um sistema autopoiético e tem a característica de poder se auto-organizar. Empregado na educação, esse conceito pode ser remetido a uma metodologia que possibilite aos alunos uma capacidade de gerar conhecimento por si, influenciando diretamente no papel do professor, que, nessa relação, passa a ser o de promover trocas com os saberes, dando valor à diversidade e individualidade de cada aluno. Nesse sentido, Santos destaca que:

O conhecimento resulta do enredamento dos aspectos do físico, do biológico e do social, considerados inseparáveis e simultâneos. Tudo o que existe no ambiente influencia o ser, que o capta e integra no processo mental de interação 
e construção. Nesse caso, impõe-se a necessidade de ressignificar, também, o próprio conceito de percepção (2008, p. 11).

Certamente é possível afirmar que o conhecimento é oriundo de uma diversidade de áreas e relações, o que permite reconhecer que existe em cada sujeito uma perspectiva de visualização do mundo, uma vez que nosso cérebro trabalha com cada estímulo enviado pelos nossos órgãos sensoriais. Ao mesmo tempo, influenciado pelo ambiente antro social, torna nossa visão cada vez mais individual e, ainda assim, possibilita compartilharmos signos e significados em uma mesma linguagem que é ao mesmo tempo individual e coletiva. O mesmo ocorre, naturalmente, com os professores.

Ao balizarmos as análises do mundo pelo paradigma simplificador, não é possível reconhecer tais individualidades, pois a percepção só poderia ser compreendida em um sentido, que vai do exterior para o interior. O conhecimento seria visto como algo puramente objetivo e independente da posição do observador, que compreenderia a tarefa de reconhecer os fenômenos que ocorrem ao seu redor por meio da memorização. Tal perspectiva castraria a visão que se tem do próprio professor na sua atividade, reduzindo-o e simplificando-o. O que é um problema, já que ele se define como um sujeito dentro de um ambiente e um ator ${ }^{\mathrm{V}}$ com inúmeros papéis a cumprir, sendo, assim, complexo.

Logo, é importante ressaltar que formas de compreensão do mundo individualizadas, ou seja, que variam de acordo com o sujeito, respaldam o pensamento complexo, ao passo que concebem os sujeitos não como passivos, mas ativos ao realizar sua leitura da realidade e do mundo. Cada sujeito, ao ler sua própria realidade e refletir sobre ela, atribui significações ${ }^{\mathrm{vi}}$ a seu sistema, composto por um contexto cultural específico que influencia sua forma de enxergar o mundo.

Cada sujeito interage com um sistema complexo, faz uma síntese singular de um tecido sociocultural, em outras palavras, há uma totalidade aberta dentro de cada um, essencialmente individual, mesmo que haja o compartilhamento de significações, combinadas em um sistema cultural.

Posto isso, Morin (2007, p. 115) trouxe a ideia da condição humana para modificar a polaridade de pensamento do homem, defendendo uma postura de pensar multidimensional, de compreender o homem como ser complexo e não como uma redução do outro. A educação deveria ser analisada, desse modo, de acordo com as mudanças desses processos e com a diversidade representada pelas diferentes visões de mundo - fazendo-se uma revisão da epistemologia complexa e da interdisciplinarmente - sobre uma realidade constituída pelo sistema cultural e por sujeitos.

A transmissão do conhecimento deve dar conta dos desafios da contemporaneidade, sem um caráter impositivo, mas sim compreensivo. As disciplinas escolares, que acabaram fragmentando-se por causa do sistema mecanicista, dificultam a conexão dos diversos conhecimentos, sobretudo, para se repensar a própria condição humana.

\section{Complexidade e natureza dos saberes docentes}

No tempo em que se vive, com tantas mudanças repentinas, as instituições e as concepções também passam por alterações. Não obstante, 
... instituições escolares se caracterizam como potencial humano para gerar novas ideias, práticas, recursos e formas de cultura ao seu redor, cujas características são as relações heterogêneas, o autodesenvolvimento contínuo, a convivência com a prática de projetos, dentre outras. São organizações alicerçadas nos valores humanos que possuem significado especial, tais como: liberdade, igualdade, paz, defesa do meio ambiente e respeito à vida. (Pinho, Ferraz, Pinho e Bringmann, 2015, p. 56).

A sociedade contemporânea, nesse contexto, enfrenta o dilema de como compreender tais transformações para incluir a escola e a educação como pontos-chave para tais mudanças. A complexidade surge como uma alternativa ao sistema vigente, trazendo um novo olhar sobre a realidade, como uma proposta de mudança do ser, conhecer e saber. Para estudar uma realidade de natureza complexa que seja produto de interdependências,

... é preciso haver novas ferramentas intelectuais compatíveis com a natureza do conhecimento a ser processado, bem como uma nova linguagem. Uma linguagem que nos ajude a evitar os reducionismos, as disjunções sujeito/objeto, a anulação do sujeito ou do objeto, bem como a fragmentação excessiva da realidade. Uma linguagem nutrida por uma epistemologia aberta, onde caibam a incerteza, a emergência, a dialógica, a recursividade, a retroação, a autoorganização, bem como o sujeito esquecido pela ciência moderna. (Moraes, 2015, p. 66).

Moraes (2015) afirma que, para compreender a natureza complexa de um fenômeno, são necessárias ferramentas intelectuais compatíveis. Assim, busca-se, por meio dos instrumentos advindos da teoria da complexidade, compreender os aspectos complexos dos saberes docentes.

A epistemologia da complexidade busca instigar tais ferramentas intelectuais para poder interligar os objetos do conhecimento, a saber, os operadores cognitivos. Tais operadores podem contribuir para se compreender a complexidade da realidade e cristalizar o pensamento, tornando-o ação e proporcionando uma materialização das dimensões lógicas e de organização da complexidade em seus diversos sentidos.

Para tanto, realizar-se-á uma reflexão, na tentativa de utilizar tais operadores como instrumentos, para compreender a natureza complexa dos saberes docentes que, para efeito, serão caracterizados no intuito de reforçar a compreensão da complexidade. Morin defende a ideia da necessidade de macroconceitos ao afirmar:

"... creo que tenemos necesidad de macro-conceptos. Del mismo modo que un átomo es una constelación... partículas, que el sistema solar es una constelación alrededor de un astro, del mismo modo tenemos necesidad de pensar mediante constelación y solidaridad de conceptos." (Morin, 2009, p. 66). 
Conforme apresentado, os conceitos não se determinariam por suas fronteiras, mas pelo que advém de seu núcleo.

Para o entendimento da complexidade, necessitamos compreender seus princípios (ou operadores cognitivos): a) princípio sistêmico-organizacional, b) princípio hologramático, c) princípio retroativo, d) princípio recursivo, e) princípio ecológico, f) princípio autoeco-organizador ou autoprodução e g) dialógico (Suanno, 2015).

Destarte, a utilização de tais princípios, para a busca de uma nova interação com a natureza dos saberes docentes, torna-se o próximo passo para o desafio proposto, em que novos esquemas mentais e intelectuais vão se formar pela relação já construída por Tardif e, agora, aplicada à luz da epistemologia complexa.

Nesse contexto, o autor (2012) questiona quais são os saberes mobilizados pelos professores, o que eles são, de onde vêm, se eles produzem outros, qual sua função. Perguntas extremamente relevantes, pois, de acordo com o mesmo autor, parte da desvalorização da própria profissão vem do não reconhecimento ou da não valorização de tais saberes que determinam seu papel e status na sociedade. Logo, a própria formação teria um problema ao caminhar para uma direção diferente do que poderia, de fato, trazer mudanças positivas na educação e na sociedade.

Certamente a presente análise não propõe uma exclusão ou substituição da teoria tardifiana acerca dos saberes docentes, pelo contrário, sugere uma ampliação e incorporação da complexidade na tentativa de melhor atender aos desafios do século XXI mencionados anteriormente. A busca de uma nova compreensão da natureza desses saberes, por meio dos operadores cognitivos, é uma tentativa de ampliar a visão complexa do mundo, embora tal visão ainda esteja bem longe de ser alcançada, uma vez que uma mudança de paradigma ainda seja necessária. Para proporcionar melhor discussão, expõem-se a seguir os saberes docentes um a um, com as supostas implicações complexas defendidas no presente artigo. Assim, propõe-se a leitura de tais saberes da seguinte forma:

\section{Saberes pessoais dos professores}

A família, o ambiente de vida, a educação no sentido lato são também saberes autoeco-organizadores, uma vez que, em todo o ambiente em que o professor esteja inserido, este se contrapõe àquele e forma a si mesmo continuamente adquirindo diversas experiências. O mundo exterior age sobre ele e o sustenta, mantendo até mesmo suas ideias sobre o que é ser professor e como deveria atuar. Uma relação que se revela hologramática, ao passo que o sujeito e a sociedade, em sua relação constante de constituição, também fazem parte de um todo social.

\section{Saberes provenientes da formação escolar}

A escola primária e secundária, os estudos pós-secundários não especializados são também saberes recursivos, dado que a linearidade da ideia de que o professor forma os alunos e, por sua vez, seus alunos que se tornaram professores formariam novos alunos, é quebrada ao se vislumbrar uma relação de cooperação de aprendizagem. Em outras palavras, o processo de aprendizagem é retroativo, o professor participa da formação do aluno e o aluno participa da formação do professor e, futuramente, esse processo volta a afetar a sua causa, pois o professor se vê novamente no mesmo ambiente escolar, só que em uma posição diferente que tivera enquanto estudante.

\section{Saberes provenientes da formação profissional para o magistério}


Os estabelecimentos de formação de professores, os estágios, os cursos de reciclagem $^{\text {vii }}$ etc. são saberes ligados à formação e são também complexos por apresentarem a característica da auto-organização. Mesmo que pensemos em programas fechados didaticamente e pedagogicamente, o professor não vai ser formado de uma maneira exata. Ele, em conjunto com o conhecimento com o qual está interagindo, formar-se-á a partir das informações coletadas em salas de aula, estágios, palestras, cursos de formação continuada, entre outros.

\section{Saberes provenientes dos programas e livros didáticos usados no trabalho}

A utilização das 'ferramentas' dos professores - programas, livros didáticos, cadernos de exercícios, fichas - mantém a complexidade no sentido do contato do sujeito com o ambiente e também do conhecimento previamente constituído relativo ao conhecimento disciplinar e didático, mas que se torna um desafio, por se apresentar como um saber, muitas vezes, pautado por um determinismo programático.

A relação com os programas demonstra um problema na formação docente quando engendra uma suposta ordem e um suposto domínio sobre o real no ambiente escolar, que parecem decidir quais caminhos os professores deveriam tomar para atingir uma ação que geraria os resultados desejados. Entretanto, a prática docente não poderia ser fomentada por tal determinismo, que teria

“... uma sequência de ações predeterminadas que deve funcionar em circunstâncias que permitem sua efetivação. Se as circunstâncias externas não são favoráveis, o programa se detém ou fracassa". Ou seja, não há como controlar todos os fenômenos que envolvem a prática do professor. (Morin, 2015, p. 90)

Muitos programas são demasiadamente fechados e não suportam o acaso, buscando determinar posturas e ações ideais, que, no contato com a realidade, produzem resultados que não condizem com as expectativas, e o professor acaba frustrando-se por não atingir aquilo que imaginava realizar de acordo com seus programas.

Conceber esses saberes como complexos condiz com pensar em estratégias, o que exige uma nova forma de conduzir as atividades, pensando na incerteza como constituinte do nosso mundo, no acaso como parte do processo. Para determinar uma estratégia, deve-se levar em conta a imprevisibilidade, na qual os eventos aleatórios fazem parte da preparação e a flexibilidade permite a mudança de rota ou postura dos professores em sua própria prática. Refletir a partir desses princípios proporciona uma melhor interatividade com o ambiente e seus acontecimentos.

Saberes provenientes da própria experiência na profissão, na sala de aula e na escola

A prática do ofício na escola e na sala de aula, a experiência dos pares, entre outros são saberes que realizam fecundo diálogo com os princípios ecológicos, posto que esses saberes baseiam-se na ação do indivíduo e que, por terem uma imprevisibilidade em suas consequências, podem gerar saberes que não estariam previstos ou presentes em outras ocasiões. A própria experiência como docente gera a identidade do professor que pode viver "n" situações em sala de aula, mas cada uma delas pode afetá-lo de maneira diferente. 
Portanto, tendo em vista todas essas relações encontradas na formação dos saberes docentes, sua natureza mostra-se plural, multifacetária e socialmente construída. Além disso, apresenta-se complexa por ser tecida em um todo, com a participação de diversos elementos que constituem uma realidade dialógica, recursiva e hologramática. Compreender os saberes dessa forma, portanto, permite conceber a inter-relação que há entre eles, que eles se relacionam dentro do próprio sujeito e que não permitem que se estabeleçam fronteiras fixas entre si. Por isso, não são saberes engavetados, os quais os professores retiram e utilizam quando precisam ou julgam necessário, como indagado por Tardif, mas, sim, são utilizados em correlações entre eles, o sujeito e o meio onde se encontram de maneira complexa.

Conceber os saberes docentes nessa perspectiva proporciona uma maior interação e também uma visão mais aprofundada da questão. Dessa forma, pode-se compreender melhor a formação de professores e buscar novas formas de transformar essas estruturas, para que se tenha condições de fomentar, nos cursos de licenciatura em geral, uma concepção de professor mais humanizada, com responsabilidade social, com uma mudança de postura e atitude que saia das normas tradicionais e ajude a superar os desafios que se apresentam na sociedade contemporânea.

As associações possíveis entre os saberes docentes e sua complexidade vão muito além das citadas aqui. Analisar o mundo através da ótica da complexidade é um enorme desafio de superação, pois ele ainda se alicerça em um paradigma simplificador, que se porta como um desafio a ser superado.

Abordar a formação docente e seus saberes na ótica complexa leva, sobretudo, a pensar a formação do sujeito. É salutar dar aos professores a possibilidade de serem tratados como seres humanos, não como máquinas burocráticas que atuam simplesmente repassando os saberes colocados por uma instituição, mas como seres que são ativos e afetivos, que possuem um prisma relacional que, cada vez mais, demonstra a necessidade de um viés humano e fraterno, considerando-os sujeitos da criação dos seus próprios saberes em sua relação com o mundo e com os conhecimentos que têm contato.

\section{Buscando conclusões e inclusões}

A busca pela natureza dos saberes docentes é um movimento necessário por estes se tratarem de aspectos profundos não só para a prática do professor, mas também para repensar sua formação, pois, por meio dessa concepção, podem-se trilhar outros rumos que não sejam dados por enfoques tecnicistas. A compreensão do professor como um sujeito é de suma importância para que ele seja tratado como um ser humano, não como uma mera máquina transmissora de conhecimento.

Há diversos elementos que devem ser considerados que vão muito além da ideia de apenas repassar conhecimentos aos alunos, seguindo um simples planejamento. Suas inter-relações geram e são geradas por uma grande quantidade de condições que não permitem que a atuação dos docentes seja completamente definida por uma postura única e fechada, desconstruindo, assim, um discurso que diz que seu sucesso será garantido por uma técnica aprendida durante sua formação. O professor precisa ser autônomo e ter sua subjetividade levada em conta. 
Assim, após reconhecer os professores como sujeitos, pode-se ter finalmente uma reflexão sobre os saberes e sua natureza, pois não haveria como compreender essas origens sem identificar qual é o ponto de partida para sua construção.

Pode-se considerar, portanto, que os saberes mobilizados pelos docentes, em suas práticas, têm uma natureza complexa por apresentarem diversas características analíticas semelhantes aos instrumentos propostos por Morin. $\mathrm{O}$ aprofundamento do pensamento de Tardif, no que tange os saberes docentes, opera, nesse sentido, uma mudança na perspectiva da formação dos professores, uma vez que oportuniza a compreensão de que um fenômeno complexo proporciona novas buscas por transformações paradigmáticas e a formulação de uma nova visão mais profunda para a superação das dualidades estruturais, da dificuldade de perceber os erros como parte do processo, da negação das contradições, da visão fragmentada do tecido complexo, da disjunção sujeito e objeto, entre outros.

Os saberes docentes, como afirmado por Tardif (2012), são socialmente construídos, plurais e multifacetários, e eles são também, como este artigo buscou demonstrar, complexos. Igualmente, carregam em si um princípio da teoria morineana: o da autoeco-organização. Enfim, o professor também se forma, não é apenas formador. Pensar que se "formam" professores assim como se "formam" alunos, nos princípios tradicionais, não deveria fazer mais parte de nossa educação. Educar para o futuro é reconhecer o papel da educação e da responsabilidade dos seres com o todo, de uns com os outros, e buscar um mundo com mais harmonia, justiça social e paz. Essas reflexões, em conclusão, pretendem abrir portas para análises complexas dos temas abordados, os quais carecem de novas perspectivas.

\section{Referências}

André, M. (2010). Formação de professores: a constituição de um campo de estudos. Educação, 33(3), pp. 174-181.

Gil, A. C. (2008). Métodos e Técnicas de pesquisa social. São Paulo, Atlas.

Lévi-Strauss, C. (1970). Antropologia estrutural. Rio de Janeiro: Tempo Brasileiro.

Maturana, H. (1995). Emociones y linguaje em educación y política. Santiago: Dolmen.

Minayo, M. C. (1994). O desafio do conhecimento. São Paulo/Rio de Janeiro: HucitecAbrasco.

Moraes, M. C. (2015). Transdisciplinaridade, criatividade e educação: fundamentos ontológicos e epistemológicos. Campinas: Papirus.

Morin, E. (2003). A religação dos saberes: o desafio do século XXI. Rio de Janeiro: Bertrand Brasil.

Morin, E. (2005). Educação e complexidade, os sete saberes e outros ensaios. São Paulo: Cortez.

Morin, E. (2007). Os sete saberes necessários à educação do futuro. 12ª . ed. São Paulo: Cortez.

Morin, E. (2004). Em busca dos fundamentos perdidos: textos sobre o marxismo. Tradução de Maria Lúcia Rodrigues e Salma Tannnus. 2a . ed. Porto Alegre: Sulina. 
Morin, E. (2015a). O Método 3: o conhecimento do conhecimento. Porto Alegre. Sulina.

Morin, E. (2015b). Introdução ao pensamento complexo. Porto Alegre. Sulina.

Morin, E. (2009). Introduccion al pensamiento complejo. Barcelona: Gedisa.

Pinho, M. J., Ferraz, E. P. N., Pinho, M. J. e Bringmann, L. O. (2015). A escola de mãos dadas com a diferenças: uma experiência de criatividade e colaboração no sul do Tocantins. In: M. J. Pinho, M. V. R. Suanno e J. H. S. (Org). Projetos criativos na prática pedagógica: cantar e encantar a aprendizagem. (pp. 55-76). Goiânia: Editora Espaço Acadêmico.

Santos, A. (2008). Complexidade e transdisciplinaridade em educação: cinco princípios para resgatar o elo perdido. Rio de Janeiro, Revista Brasileira de Educação, 13(37), pp.71-83.

Santos, A. (2009). Complexidade e transdisciplinaridade em educação: cinco princípios para resgatar o elo perdido. In: A. Santos e A. Sommernann (Org.). Complexidade e transdisciplinaridade: em busca da totalidade perdida. (pp. 1538). Porto Alegre: Sulina.

Suanno, M. V. R. (2015). Didática e trabalho docente sob a ótica do pensamento complexo e da transdisciplinaridade. Tese de Doutorado em Educação. Programa de Pós-Graduação Stricto Sensu em Educação. Brasília: Universidade Católica de Brasília - UCB.

Tardif, M. (2012). Saberes docentes e formação profissional. 13 ${ }^{\text {a }}$ ed. Petrópolis: Vozes.

Zwierewicz, M. e Torre, S. (Org.) (2009). Uma escola para o século XXI: escolas criativas e resiliência na educação. Florianópolis: Insular.

\footnotetext{
' Por natureza entende-se que se busca neste artigo o núcleo do fenômeno aqui estudado, sua essência e, dessa forma, considera-se que a necessidade de se estudar os saberes docentes vai além da compreensão dos saberes em si, buscando-se também refletir sobre como esses saberes são determinados e repassados, visto que tal interação é capaz de transformar uma dada realidade social.

ii Princípio que se expressa na recursividade, pois ao mesmo tempo em que esses sistemas são autônomos, são também dependentes, são antagônicos e também de complementam.

iii Estar em um movimento mútuo com algo, de forma que ambas as partes se modifiquem, interagindo e atuando em um mesmo movimento aberto e de trocas constantes.

iv Conceito inicialmente trabalhado por Maturana e Varela (1995) e posteriormente empregado por Edgar Morin como um dos princípios da Complexidade.

${ }^{\vee}$ Como ator, refiro-me à metáfora da atuação dos sujeitos em diversos campos sociais que exigem papéis diferentes a serem interpretados como no teatro.

vi Segundo Lévi-Strauss (1970), a significação é uma relação entre significantes e significados que constituem um modo simultâneo e solidário de visão de mundo.

vii A expressão "curso de reciclagem" é utilizada por Tardif em seu livro Saberes Docentes e Formação Profissional (2012) e foi empregada aqui para manter a fidelidade do texto original. Assim sendo, considera-se que seria mais apropriado utilizar "atualização" ou "aperfeiçoamento".
} 
de Pinho, M. J. e da Silva, B. L.

Data de recebimento: 04/11/2017

Data da revisão: $26 / 12 / 2017$

Data do aceite: 27/12/2017 